\title{
Main Factors of Turnover and Minimization of Turnover Rate within Business Organization
}

\author{
Mariya Aleksandrova Ivanova \\ New Bulgarian University, Sofia, BULGARIA \\ Department of Administration and Management
}

Received 26 August 2019 • Revised 15 November 2019 • Accepted 18 November 2019

\begin{abstract}
The report presents the turnover problems in a call center positioned in Bulgaria. This research identify the main reasons of high turnover within business case study and to identify key actions that could be done to decrease the turnover rate. The recommendations drawn from the research of a particular company may serve the project managers of other call center companies. But leaders need to consider the specificity of their organizations and make a similar study of key factors, benchmarking the results of the study presented here, and only then plan action steps for change.
\end{abstract}

Keywords: turnover problem, level of stress, poor management, lack of career growth and development, lack of recognition.

\section{Introduction}

Turnover problem has been one of the main topics of scientific researches in the human resources and organizational behavior field for more than 40 years.

This article presents the results of a case study. This research was done within a call center positioned in Bulgaria by a well-known international organization TELUS International Europe. The research was carried out through the collaboration of a team of researchers at New Bulgarian University and a student who is an employee holding a key position in the selection and training department.

The Case Study: TELUS International Europe is a multilingual contact center, BPO (business process outsourcing) and ITO (information technology outsourcing) provider that was founded in Sofia in 2004. Currently the company has around 3,500 team members in Bulgaria, Romania and England. In 2014 the company became part of TELUS International - global BPO company with over 28 ,000 team members around the world with headquarters in Canada.

TELUS International offers outsourcing services in following spheres: contact centers, back-office administration, finance and accounting, supply chain management, IT, analytics and business intelligence, business process improvement and others.

(C) Authors. Terms and conditions of Creative Commons Attribution 4.0 International (CC BY 4.0) apply. Correspondence: Assist. prof. Mariya Aleksandrova Ivanova, Department of Administration and Management, New Bulgarian University, Sofia 1618, j.k. Ovcha kupel, Montevideo 21, BULGARIA. E-mail: maivanova@nbu.bg. 
The organizational structure of TELUS is project-based, meaning that for each project a separate team is chosen, headed by project manager and supervisors. Projects can be in different areas, usually employees from different projects do not communicate with each other on a regular basis. This is the reason of why job satisfaction of employees and turnover rate can differ significantly between different projects.

Object of research is Project $\mathrm{X}$ that has more than 100 employees, it deals with inbound calls and e-mails from customers in 10 different languages. Therefore, the whole team is divided into 4 smaller teams that serve different markets: Russian market, German market, CEE Market (including Poland, Hungary, Romania and Bulgaria) and Mediterranean Market (including Greece, Israel and Turkey).

Subject of study. One of the main problems that each call center has to combat is the problem of high turnover. In our project the turnover rate exceeds $30 \%$, which is much more than expected by the management of the company. Interestingly, turnover rate differs significantly even within the same project, but between different markets. For example, 11 out of 21 current members of Russian market team are employees that have worked less than 1 month in the project (they are all newcomers), and at the same time during the first 5 months of 2018 year 6 employees left the team. It shows that only for 5 months of this year the turnover rate within Russian market team exceeds $35 \%$.

The main goal of this research is to identify the main reasons of high turnover within our project $\mathrm{X}$ and to identify key actions that could be done to decrease the turnover rate.

In order to achieve this research goal the following tasks should be performed:

- To identify the essence and the main reasons of turnover by reviewing the literature on this topic;

- To identify the main expectations of newcomers within the project X;

- To identify the main reasons of turnover within project X;

- To identify factors that have the biggest impact on turnover rate within project $\mathrm{X}$, and whether expectations of newcomers are fulfilled or not;

- To propose actions for reducing turnover rate within project X.

2. Research background and theoretical framework

In 1977 turnover was defined by Price as "the ratio of the number of the organizational members who have left during the period being considered divided by the average number of people in that organization during period”. In 1995 Woods looked at turnover from a different perspective and described it as "replacement cycle" - a time, when position is vacant after dismissal of previous employee and when new employee has to be found and hired. In 2000 Abassi defined turnover in a much broader perspective - as movement of employees not only in and out of an organization, but as movement of employees around the labor market: between firms, jobs, between states of employment and unemployment.

Turnover is usually perceived automatically as a bad and undesirable process. However, turnover can also have positive impact on the organization, depending on whether high performers or low performers are leaving. This is the reason why the typology of turnover has been elaborated (Allen, 2008):

- Voluntary (initiated by the employee) and involuntary (initiated by the organization);

- Functional (is not harmful for the organization) and dysfunctional (is harmful for the organization); 
- Unavoidable (is caused by factors over which organization does not have control) and avoidable (is caused by factors over which organization has control).

Iqbal (2010) in his article also defined two types of involuntary turnover: discharge turnover (dismissal of individual employee due to discipline or job performance problem) and downsizing turnover (part of organizational restructuring and/or cost-reduction program).

In general, all studies on turnover can be divided into 3 main groups: defining main reasons of employee turnover, defining effects of employee turnover on organization and elaboration of main strategies to minimize the turnover rate.

Usually, each employee's decision to leave is determined by some shock (positive or negative) and falls within one of the following 4 paths:

- Dissatisfaction - the most traditional reason of turnover, when employee perceives that he/she is giving more to the organization than he/she is receiving from the organization, or when employee understands that his/her capabilities are wider than / or do not correspond with the requirements of the position;

- Better alternative - the situation when employee may be even satisfied with his/her current position, but receives better proposal (for example, in terms of remuneration or career advancement);

- Following a plan - the situation when employee leaves the organization according to a certain pre-defined plan (for example, when employee leaves the company due to pregnancy);

- Not following a plan - turnover as a result of some impulsive reaction of employee (for example, being passed over for a promotion).

Most of the researches dedicated to the problem of voluntary turnover are highly practical and study turnover in a certain organization or in a certain sector. This can easily be explained by the fact that voluntary decision to quit is always individual and can differ from person to person, even within the same organization. Therefore, the more precise is the sample for the research, the more practical will be the conclusions, and the more beneficial it will be for the organization.

As an example, research of Robert D. Gardner (2010) in his study on the factors that influence turnover of K-12 (meaning primary and secondary education) music teachers in the United States came to the conclusion that there are some factors of turnover that are specific for that category of teachers:

- Music teachers receive less support than other teachers for work with children with special needs;

- There is lack of a music supervisor support (that could handle large part of the administrative work), meaning lack of administrative support (this factor is especially crucial for male teachers);

- Music teachers that work part-time and have to visit separate buildings during the day are more likely to quit than those who work full-time and spend the whole working day in one building etc.

This is an example of a research of turnover problem in one single profession. However, currently there are more than 40,000 different professions all over the world and the reasons of turnover can differ significantly among them. 
Our study is aimed to investigate the turnover problem in the project $\mathrm{X}$ of TELUS call center. Therefore, the specific literature on turnover problems in call centers can be useful for our research.

So far, many scientists have examined the problem of turnover in various call centers in different parts of the world. Although most of the call centers are considered to have a lot in common - for example, the presence of the so-called "emotional burnout", when agents have to face negative emotions of clients on a daily basis, or the need to "hide emotions", when in each conversation agents have to maintain pleasant tone of their voice, even when they have negative emotions - they can also significantly differ.

A lot depends on the type of service that is provided by the call center - whether it is just receiving orders for delivery of pizza, or it is request to repair IT systems. Also, some call centers may specialize in outbound calls, while others work only with inbound calls. Obviously, the level of emotional burnout should be greater in outbound call centers because of high percentage of rejections from the part of the customers.

Therefore, the results of scientific researches on identifying the main reasons of turnover in a call center can differ significantly. Part of the researches make accent on the performance indicators that influence the turnover rate, while another part come to the conclusion that performance is not that important as level of job autonomy, job satisfaction and supervisor's support.

For example, one of the recent studies conducted by Italian researchers M. Zito, F. Emanuel, M. Molino, C. G. Cortese, C. Ghislieri, and L. Colombo (2018) in the call center of Italian Telecommunication Company, proved that emotional dissonance has a positive relation with turnover intentions, while job satisfaction, supervisor's support and job autonomy have a negative relation with turnover intentions. Researchers also proved that job satisfaction can be a mediator in negative relation between job resources (supervisor's support and job autonomy) and turnover intentions, as well as a mediator in positive relation between emotional dissonance and turnover intentions.

At the same time, another study, conducted by Chilean researchers M. A. Valle and G. A. Ruz (2015) in one of the Chilean call centers specialized in outbound calls for selling insurance services, proved that performance indicators (mostly the number of sales and amount of sales) during the first 2 months of work influence the turnover intentions of agents in the following months. They also proved that dynamics of performance indicators is even more important, as those employees who have positive dynamics in performance tend to stay in the company, and those who have negative dynamics tend to leave the company.

Another research, conducted by Malcolm C. McCulloch and Daniel B. Turban (2007), studied the problem of person-organization fit (P-O fit) in general and its impact on turnover intentions. They distinguished complementary fit (when candidate possesses skills and knowledge that organization is missing) and supplementary fit (when individual values and values of organization coincide). The results of the study show that $\mathrm{P}-\mathrm{O}$ fit has positive relation with turnover intentions and it can be used to predict the turnover rate. Interestingly, researchers did not find support for their hypothesis that $\mathrm{P}-\mathrm{O}$ fit is positively related with job performance of agents, and it cannot be used for prediction of job performance.

The last two researches described above demonstrate the existence of specificities in every single call center, and while in one call center there may be strong relation between job performance and turnover, in another call center this relation may not exist at all. 
Following the range of other articles on this topic, we would make the following list of possible reasons of turnover:

- Job stress;

- Lack of commitment to the organization;

- Job dissatisfaction;

- Economic reasons (low salary);

- Lack of job autonomy;

- Lack of role clarity;

- Ambiguity of performance evaluation methods;

- Organizational instability;

- Absence of openness in sharing information;

- Toxic workplace environment;

- Lack of recognition;

- Inconvenient working schedule;

- Corporate culture and management style;

- Lack of opportunities for future development.

As job satisfaction/dissatisfaction itself is a quite complex phenomenon, many scientists examine the main factors that influence job satisfaction. For example, Stewart and Brown (2011) defines 6 dimensions of job satisfaction: satisfaction with empowerment, with job fulfillment, with pay, with work group, with security and with work facilitation.

Henry Ongori (2007) in his article also pays attention to the effects of turnover on the organization: costs for searching, hiring and induction of a substitute employee; overtime payment for existing employees; reduction of profitability of a company; worsening of customer service and customer satisfaction level etc. I would add to that list the effect on overall corporate culture and image of employer for potential external candidates, as well as for existing employees.

In fact, turnover can have a significant negative effect on organizational effectiveness, so it is very important to identify the main factors of turnover and to elaborate plan that will mitigate impact of those factors. This problem is very practical and in our research it is important to identify factors of turnover that exist exactly in our project X in TELUS.

\section{Empirical research}

This current conducted empirical study does not claim to be fully comprehensive. It is limited within a relatively small group of subjects with relatively homogeneous age limits. But its results make it possible to draw conclusions about a little research topic in Bulgaria and provoke discussions with other researchers in this field.

\section{Methodology and approach of research}

As it has been mentioned before, this study is aimed to achieve following research

goals:

- To identify expectations of newcomers within the project X;

- To identify main reasons of turnover within the project X;

- To identify factors that have the biggest influence on turnover within

project X, and whether expectations of newcomers are fulfilled or not;

- To propose actions that could reduce the turnover rate. 
In order to achieve the first goal 11 newcomers (that have joined the company during the last 1 month) were asked 2 open questions:

- Why did you decide working in this project?

- In your opinion, what is the main difficulty that you will have to face at your new position? newcomers.

After that the responses were analyzed to figure out what are the expectations of

Similarly, the best way to understand why people are leaving is to ask them directly. Therefore, to achieve the second research goal we could use either the method of exit interviews with those employees that are going to leave the company within following 3 months (i.e. they have already signed resignation letter and are within notification period) or the method of interviews with those employees that have left the company during the last 6 months (i.e. they still remember well the reasons of leaving the company).

Due to constraints of the first method (we are not allowed to conduct exit interviews with employees and do not have access to the database of exit interviews), we used the second method - interviews with employees who have left the project during the last 6 months.

These are employees that occupied different positions within the project: 2 employees from Back-office (that conduct manual calculations, issuance and reissuance of documents); 1 employee from Mentors (that provide support for other agents on the platform, answering all kind of questions related to performing project tasks) and 7 employees from Front-office (that receive phone calls and answer e-mails).

Questions in those interviews were mostly open with the main one - "What are three main reasons (ranked by importance) that made you to leave the project?". All answers were grouped into categories (low salary, lack of recognition etc.), which gave us the possibility to calculate the most frequently mentioned categories. Also, the first answer in individual ranking received 3 points, the second -2 points, the third -1 point. In this way it was possible to examine a little bit deeper the importance of each category. The results of those interviews are shown in the following chapter of this research - "Results".

However, in order to understand fully the problem of turnover it is important not only to ask those who left about why they left, but also to ask those who stayed about why they stayed. This approach is making accent on the "other side of the coin", identifying good aspects of the organization of work process, and factors that motivate employees to stay. However, by ranking those factors it is possible to identify factors that contribute the least to the intentions of employees to stay, and, therefore, can be considered as factors of turnover in the future.

For this purpose also the method of stay interviews could be used, but in order to provide anonymity we have chosen the method of survey.

Currently there are 110 employees, working in our project X. We have designed a questionnaire and have asked 20 employees ( $18 \%$ from the total amount) to fill it in. In order to provide reliability of results questionnaire was given to different categories of employees: 1 mentor, 2 Back-office specialists, 1 quality specialist and 16 Front-office agents.

There were 13 closed questions:

1. I have exciting, challenging and meaningful work.

2. I have supportive management / good boss.

3. I feel recognized, valued and respected for my job performance.

4. I have enough opportunities for career growth, learning and development within the project. 
5. I have a flexible work schedule.

6. I receive appropriate amount of salary for the work I perform.

7. Job location is convenient for me.

8. I feel that my position is secure and I will not be dismissed in the future.

9. I am proud of organization I am working for.

10. My manager possesses needed skills and knowledge to perform his job well.

11. I can deal with stress at work well.

12. I have enough independence in performing my job.

13. I rarely think about quitting my job.

And with the scale offering 5 possible answers: "Strongly disagree" (1 point), "Disagree" (2 points), "Neither" (3 points), "Agree" (4 points), "Strongly agree" (5 points). Then the average score was calculated for each answer, describing the level to which certain characteristics of the job are present in our project. It was also decided to analyze the differences between males ( 8 respondents) and females (12 respondents), as well as between employees, working in project less than 1 year (10 respondents), from 1 year to 2 years (6 respondents) and more than 2 years (4 respondents). For each of the above-mentioned categories of personnel average score was calculated as well.

The final step was to compare the results of interviews with those who already left the company and the results of the survey among existing employees.

All the participants of the survey were informed that the research was conducted with learning purpose only and all answers were kept anonymous.

5. Findings and research results

After asking newcomers about their expectations we have elaborated the list of factors that attract candidates to work in our project:

- Interesting job;

- Good salary;

- Good benefits;

- Flexible work schedule.

Among possible difficulties that may be faced at new position newcomers mentioned primarily the need to learn a lot of procedures and to handle complex tasks, as well as multitasking. However, only 4 of them mentioned that the main difficulty is job-related stress and need to hide emotions.

The results of interviews with employees who have already left the company during the last 6 months, demonstrated that the absolute "leader" among factors is Poor management (see Table 1). It actually proves the typical saying that "employees join the company, but leave the manager".

The second important factor is Low salary - it can be explained by the fact that almost all of the interviewees found a greater-paid job after they left our project. This means that currently the BPO market can offer greater level of payment and this is a problem to which special attention should be paid by the management of the project.

Other factors were mentioned more or less with the same frequency. However, the third important factor is Job-related stress, which can partially be explained by the fact that work in call centers is characterized by emotional dissonance and need of hiding emotions. However, as many of employees just changed one call center to another, it can mean that in our project this 
issue (emotional dissonance) is not considered a big problem and management does not act in a proper way to reduce its impact.

Table 1. Factors of leaving the company by employees who left during the last 6 months

\begin{tabular}{|l|c|}
\hline Reasons of leaving the company & Total score \\
\hline Low salary & 13 \\
\hline Poor bonus system & 4 \\
\hline Poor management & 18 \\
\hline Lack of opporunities for future development & 5 \\
\hline Job-related stress & 7 \\
\hline Lack of job autonomy & 5 \\
\hline Lack of recognition & 3 \\
\hline Inconvenient job location & 5 \\
\hline
\end{tabular}

The results of the survey conducted among existing employees (see Table 2) show that the most dissatisfying factors are poor management, lack of recognition and lack of career growth and development. At the same time, there are 2 factors that are considered as big advantages flexible work schedule and job security. All other factors have neutral value.

Table 2. Factors of staying in the project

\begin{tabular}{|l|c|c|c|c|c|c|}
\hline $\begin{array}{l}\text { Factors of staying } \\
\text { within the project }\end{array}$ & Average & $\begin{array}{c}\text { Average } \\
\text { (Male) }\end{array}$ & $\begin{array}{c}\text { Average } \\
\text { (Female) }\end{array}$ & $\begin{array}{c}\text { Average } \\
(\mathbf{0}-1)\end{array}$ & $\begin{array}{c}\text { Average } \\
(\mathbf{1 - 2})\end{array}$ & $\begin{array}{c}\text { Average } \\
(>\mathbf{2})\end{array}$ \\
\hline Exciting work & 3.7 & 3.4 & 3.9 & 4.2 & 3.5 & 2.8 \\
\hline $\begin{array}{l}\text { Supportive } \\
\text { management }\end{array}$ & 2.8 & 2.4 & 3.1 & 3.8 & 1.8 & 1.8 \\
\hline Recognition & 2.7 & 2.4 & 2.9 & 3.6 & 2.0 & 1.5 \\
\hline $\begin{array}{l}\text { Career growth and } \\
\text { development }\end{array}$ & 2.8 & 2.5 & 2.9 & 3.4 & 2.2 & 2.0 \\
\hline Flexible work schedule & 4.0 & 3.9 & 4.0 & 4.2 & 3.8 & 3.5 \\
\hline Decent salary & 3.4 & 3.0 & 3.7 & 4.0 & 2.8 & 2.8 \\
\hline Secure position & 4.1 & 4.0 & 4.2 & 4.3 & 3.8 & 4.0 \\
\hline Pride for organization & 3.4 & 2.9 & 3.8 & 3.8 & 3.3 & 2.5 \\
\hline Highly skilled manager & 3.7 & 3.8 & 3.7 & 4.3 & 3.3 & 2.8 \\
\hline Dealing with stress well & 3.5 & 3.4 & 3.5 & 3.2 & 3.7 & 3.8 \\
\hline Job autonomy & 3.6 & 3.1 & 3.9 & 3.7 & 3.3 & 3.8 \\
\hline Intentions to stay & 3.3 & 2.8 & 3.7 & 4.1 & 2.7 & 2.3 \\
\hline Total & 3.4 & 3.1 & 3.6 & 3.9 & 3.0 & 2.8 \\
\hline
\end{tabular}

*red - critical factors; white - neutral factors; green - positive factors.

For males' poor management is among critical factors, while for females it is among neutral factors. For those who work less than 1 year in the project, there are much more positive factors than for others, including exciting work, decent salary, highly skilled manager and overall Intentions to stay. So, at this point we can state that many of expectations of newcomers are fulfilled, especially with regards to interesting job, good salary and flexible work schedule.

Those who work from 1 to 2 years are dissatisfied with their salary, and are thinking about quitting the company. Those who work more than 2 years, also demonstrate dissatisfaction with job content, corporate culture, and level of skills of manager. 
Among other factors it is important to mention that job-related stress is more spread among employees who work less than 1 year in a project. Job autonomy and job security have almost the same value for all categories of employees.

\section{Discussion}

As it has been already mentioned in the previous chapter, the results of research show that expectations of newcomers are usually fulfilled - they get good salary, good benefits and they perceive their new job as exciting and interesting. However, employees with greater tenure demonstrate lower level of engagement, as those factors (salary, benefits and job content) have short-term effect and cannot maintain high level of engagement of employees for a long period of time.

Comparing the results of interviews with employees who have recently left the project and the results of the survey among existing employees, we can notice that poor management is the most important reason of turnover. Poor management means lack of managerial support, lack of regular feedback, taking wrong decisions and poor team management. Consequently, level of engagement of employees is decreasing and they leave the project. Interestingly, employees who work in the project for less than 1 year evaluate level of management relatively well, but those who work more than 1 year, mention poor management as very dissatisfying factor.

Overall in the project around 40\% employees have experience of more than 1 year in the project, meaning that they can leave the project in the nearest future because of poor management.

Interestingly, other factors of turnover differed between those who already left the company and those who still work within the project.

For those who left, low salary was the second factor of turnover, but the average score from the survey showed that for existing employees this is a neutral factor. Nevertheless, it is possible to notice that employees with greater tenure (more than 1 year) also mention low salary as a negative factor. It can be explained by the fact that salary of employees with greater tenure is usually not greater than salary of newcomers. Therefore, "old" employees feel it is unfair that having more experience they receive the same salary, and many of them decide to leave, especially if they find jobs with greater salary on the job market.

The other problem with regards to remuneration is that "old" employees usually perform more diversified tasks than newcomers: they answer calls from corporate clients, respond on e-mails, answer calls from premium customers etc. However, this difference in the amount of work performed is not reflected in the salary they receive.

The third important negative factor mentioned by existing employees is lack of opportunities for career growth and development. Again, employees with greater tenure complain more often about that. As the majority of respondents were representatives of Front-office, they may feel that it is very difficult to be promoted to a higher position within the project, although having experience of more than 1 year they feel that they deserve a promotion.

However, those who left the company did not mention lack of career prospects as one of the main reasons of turnover. This underlines the fact that this factor is not as crucial for changing job as poor management and low salary. Many of employees, who left, started working in another company at position of the same level as their previous position within the project.

Job-related stress and difficulty in dealing with it is not among negative factors for each of the categories of existing employees, but it is the third factor of turnover within employees who already left the project. Job-related stress is especially common among newcomers and can 
be the reason of turnover within the first 6 months. As for our research we took a wider range for classification (o-1 year), we were not able to observe importance of this factor among newcomers, and this problem should be studied additionally.

Lack of recognition was not often mentioned by employees who left the project, but at the same time it was often mentioned by existing employees. It can be explained by the fact that existing bonus system does not encourage employees to do the work of high quality, it only encourages employees to have as many transactions (calls and e-mails) as possible. In this situation "old" employees, obviously, perform work of a much higher quality than newcomers, but they do not receive a much higher bonus for that.

However, lack of recognition itself does not force employees to leave the project, because they understand that in a new company they will have to start creating their image from the very beginning, and it can take a long time before they will receive recognition at their new position.

Two positive factors that already now help to retain employees within the project are the following: flexible working schedule and job security. Moreover, nobody from those who left the project complained about flexibility and job security as well. Those factors can attract mostly 2 categories of employees: students, who need to combine their studies with earning the living, and employees who need stable income (for example, parents who have small children, those who need to pay loans etc.).

It is important to mention that although other factors such as poor job content, low skill level of manager and poor corporate culture are not frequently met among employees in general, at the same time they are quite often met among employees with greater tenure. This can be explained by the limits of the job content - at a certain point employee just stop learning something new, repeat similar tasks during the day, and at the same time they feel that they can do much more than they do now, and they leave the company. This is the reason of why there are so few employees with tenure within the project of more than 2 years.

\section{Recommendations}

As the research showed, there is a lot to do by the management in order to reduce the turnover rate, and there are many factors to which they have to pay attention to:

(1) Newcomers that join the company are not always acquainted with the level of stress that they will have to face. They are excited by the job content, good salary and good benefits, but many of them become demotivated during the first months of their job, because they are not prepared for job-related stress. In order to secure smoother adaptation of newcomers to the excessive workload during the first month every newcomer should have a mentor who could sit next to them and explain all nuances and details. In this way newcomers will be able to adapt much quicker. Management could also introduce separate bonus for mentors who do their job very well. Apart from that, recruitment process should be improved as well in order to prevent hiring employees who cannot deal with stressful situations and high workload.

(2) Poor management - most of employees who occupy currently the managerial position started their career within the project from the lowest position. This career growth is good as it demonstrates the possibility of the company to grow up their own managers. However, existing managers have good professional skills (i.e. they know all the processes and can assist agents 
in their work) but they miss managerial skills. Possible solution to that - to provide soft skills training for them, to provide mentoring and coaching from the part of those managers that have greater tenure within the company.

(3) Low salary level and poor bonus system - those 2 factors go together, because they form the remuneration of every employee. Unfortunately, today there is no significant difference in the level of pay between Front-office agents, Back-office agents, Mentors, and the accent of bonus system is done on quantity, not quality. The solution to this could be creation of salary grid for different categories of employees, as well as new bonus system with better balance between quality and quantity.

(4) Lack of career growth and development - unfortunately, in a call center there are not many possibilities for career growth. However, every employee can continue their personal development along with their job. They can be encouraged to read books, scientific articles, attend seminars on their interest. And here the role of supervisor is important who has to conduct regular career development meetings with employee, giving advices and new directions of development for employees.

(5) Lack of recognition - management should create the system of "small" rewards. For example, to reward unexpectedly employees who handled well a very difficult case, or who paid attention to discrepancies between knowledge portals that they use for their work. It could be some small goody, or just simple "Thank you" from the boss, but it should be incorporated into day-to-day work, and to become part of corporate culture.

As it can be seen, all the above-mentioned actions are quite real and can be introduced into practice. Of course, financial aspects should be taken into consideration as well, because many of those actions can be quite costly, and the project budget is quite limited. However, step by step, with the implementation of proper strategy, it is possible to reduce significantly turnover rate within our project, and to improve the results of the project as a whole. Project Manager, together with supervisors have to take responsibility for elaboration of such strategy, and HR Business Partner has to assist them in order to provide them with necessary tools for HR management.

\section{Conclusion}

The recommendations drawn from the research of a particular company may serve the project managers of other call center companies. But leaders need to consider the specificity of their organizations and make a similar study of key factors, benchmarking the results of the study presented here, and only then plan action steps for change.

\section{Acknowledgements}

This research did not receive any specific grant from funding agencies in the public commercial, or not-for-profit sectors.

The author declares no competing interests. 


\section{References}

Allen, D.G. (2008). Retaining Talent - A guide to analyzing and managing employee turnover, last seen in $\quad$ https://www.shrm.org/hr-today/trends-and-forecasting/special-reports-and-expertviews/Documents/Retaining-Talent.pdf.

Gardner, R. D. (2010). Should I stay or should I go? Factors that influence the retention, turnover, and attrition of K-12 music teachers in the United States, Pennsylvania State University, Pennsylvania, USA, Journal Arts Education Policy Review, 111(3).

Iqbal, A. (2010). Employee turnover: Causes, consequences and retention strategies in Saudi organizations, Prince Sultan University, Riyadh, Saudi Arabia, last seen in https://www.researchgate.net/publication/215912138 Employee Turnover Causes Conseq uences_and_Retention_Strategies_in_Saudi_Organizations.

McCulloch, M. C., \& Turban D. B. (2007). Using person-organization fit to select employees for highturnover jobs, International Journal of Selection and Assessment, last seen in https://onlinelibrary.wiley.com/doi/abs/10.1111/j.1468-2389.2007.00368.x.

Ongori, H. (2007). A review of the literature on employee turnover. University of Botswana, Botswana, last seen in https://www.researchgate.net/publication/209835787_A_review_of the literature_on_em ployee turnover.

Stewart G. L., \& Brown, K. G. (2011). Human resource management: Linking strategy to practice, Publisher: Wiley, ISBN-13: 978-0471717515, ISBN-10: 0471717517

Valle, M. A., \& Ruz G.A. (2015). Turnover prediction in a call-center: Behaviorial evidence of loss aversion using Random Forest and Naïve Bayes algorithms, Journal Applied Artificial Intelligence An International Journal, 29(9).

Zito, M., Emanuel, F., Molino, M., Cortese, C. G., Ghislieri, C., \& Colombo, L. (2018). Turnover intentions in a call center: The role of emotional dissonance, job resources, and job satisfaction, PLoS One. 2018 Feb 5;13(2):e0192126. doi: 10.1371/journal.pone.0192126. eCollection 2018, last seen in https://www.ncbi.nlm.nih.gov/pubmed/29401507. 